\title{
Away With SWOT Analysis: Use Defensive/Offensive Evaluation Instead
}

Erhard K. Valentin, (E-mail: evalentin@weber.edu), Weber State University

\begin{abstract}
SWOT analysis, which delves into a business' strengths, weaknesses, opportunities, and threats, is used widely in firms and classrooms to distill fragmentary facts and figures into concise depictions of the strategic landscape. Yet despite its popularity and longevity, the SWOT approach to situation assessment often is ineffective. This article begins with a brief critique of the SWOT framework and typical SWOT analysis guidelines. Thereafter, Defensive/Offensive Evaluation (DOE) is advanced as an effective alternative to SWOT analysis. Because DOE is more theory-driven, it poses keener questions and promises more illuminating answers.
\end{abstract}

\subsection{INTRODUCTION}

WOT analysis entails portraying a business' internal context in terms of strengths and weaknesses and scouring its external context for opportunities and threats. It is meant to spark strategic insight and distill fragmentary facts and figures into coherent backdrops for strategic planning (Mintzberg 1994). Superior strategic insights are scarce intellectual assets that facilitate securing competitive advantages, while ignorance and strategic misconceptions often comprise costly deficits (Barney 2002; Glazer 1991; Srivastava, Shervani, and Fahey 1998).

SWOT analysis is used widely in firms and classrooms; frequently it is the centerpiece of situation assessment (Day 1984). However, despite its popularity and longevity, SWOT analysis yields banal or misleading results so frequently that Hill and Westbrook (1997) advised scrapping it. Troublesome implicit premises that underlie the SWOT framework and typical SWOT analysis guidelines are addressed briefly in this article. Thereafter, Defensive/Offensive Evaluation is advanced as a more systematic and more effective approach to situation assessment.

\subsection{THE TROUBLE WITH SWOT ANALYSIS}

SWOT analysis has shallow theoretical roots. They run no deeper than the tenet that, like any living organism, a business can prosper only if it achieves a good fit between itself and its environment. Although this assertion is eminently plausible, SWOT analysis also rests on the rather shaky suppositions that every strategically significant feature of a business' internal and external context can be categorized neatly as favorable or unfavorable and such categorizing affords strategic insight. While neither the SWOT matrix, shown in Figure 1, nor its conceptual underpinnings shed light on how noteworthy particulars are to be identified and classified correctly or how strategic implications are to be derived, supplemental guidelines abound. They usually are fortified with checklists, which enumerate myriad factors and forces that might affect a business.

Unfortunately, conventional SWOT guidelines offer little more than menus of assorted generic strengths, weaknesses, opportunities, and threats (SWOTs). Further:

Figure 1: The SWOT Matrix

\begin{tabular}{|l|c|c|}
\hline & Internal Factors & External Factors \\
\hline Favorable Factors & STRENGTHS & OPPORTUNITIES \\
\hline Unfavorable Factors & WEAKNESSES & THREATS \\
\hline
\end{tabular}


- $\quad$ Typical SWOT guidelines promote superficial scanning and impromptu categorizing in lieu of methodical inquiry. They leave the false impression that noteworthy particulars can be spotted at a glance and their likely impact (favorable or unfavorable, major or minor) is obvious and independent of context. Hence, they prompt analysts to reflexively equate the likes of stricter impending regulations with threats and rapid market growth with opportunities. Yet, circumstances that threaten some contestants usually extend opportunities to others; and many apparent opportunities evaporate when examined in light of the competitive context. Thus, contrary to the intimations of prevalent SWOT guidelines, many features of a business' internal and external context are not intrinsically good or bad. Instead, strengths and weakness define and are defined by opportunities and threats. Strengths facilitate thwarting potential threats and realizing apparent opportunities, while weaknesses render a business vulnerable or incapable of creating adequate value for customers and shareholders.

- $\quad$ The SWOT framework does not readily accommodate tradeoffs. For example, does Southwest Airlines' lack of customary in-flight meals constitute a strength or a weakness? From one vantage point, no meals puts Southwest at a disadvantage. However, serving meals would diminish Southwest's key advantage, low cost. Aside from raising out-of-pocket cost, it would increase opportunity cost because more time would be used to service planes, leaving less revenue-generating flying time (Porter 1996). Clearly, Southwest's no-meals policy is too important to ignore. Yet, debating which SWOT quadrant pinches least or whether no meals might be a weakness that, paradoxically, underlies a strength wastes time better spent diagnosing and articulating the complex effects of no meals on competitive advantage and customer value. Moreover, categorizing Southwest's dearth of customary amenities as weaknesses while listing effects (lower costs) among strengths is confusing and beclouds that "rectifying" the apparent "weaknesses" would diminish corresponding strengths. In sum, tradeoffs and their consequences are among various strategically significant phenomena that are complex, dynamic, and systemic. They seldom can be depicted effectively by simplistic, static, taxonomic schemata, such as SWOT matrices.

- $\quad$ SWOT guidelines commonly muddle accomplishments and strengths. For instance, market-share leadership is an accomplishment listed as a strength in Kotler's (2003) checklist. Calling it a strength may seem apt because frontrunners must be doing something right; studies have shown direct correlations between market share and earnings (Buzzell, Gale, and Sultan 1975); and advantages rooted in network externalities and scale and experience economies are contingent on market-share leadership (Arthur 1996; Ghemawat 1986; Grant 2002). Nevertheless, reflexively equating market-share leadership with competitive advantage or strength is imprudent because the implied causal relationship between volume and advantage may no longer exist or may never have existed (Jacobson and Aaker 1985). When market-share leadership, early entry, or other accomplishments do seem to underlie current advantages, then the specific advantages should be enumerated (e.g., cost leadership) and their sources noted (e.g., superior scale economies and bargaining power derived from market share).

- $\quad$ SWOT guidelines generally lack criteria for prioritizing SWOTs. Hence, items are listed as if all were equally important, and critical matters often are obscured by clutter.

The preceding list comprises only a partial inventory of shortcomings that commonly plague SWOT analyses and SWOT guidelines. Better instructions could mitigate some flaws (Valentin 2001). But as Hill and Westbrook (1997) intimated, improving situation assessment markedly entails replacing SWOT analysis, not merely refining it. The proposed replacement - Defensive/ Offensive Evaluation - reflects the aims of systems analysis, rather than taxonomy, and provides analysts with a better sense of what to look for when surveying the strategic landscape and pondering the internal-external nexus.

\subsection{DEFENSIVE/OFFENSIVE EVALUATION: AN ADVANCED FRAMEWORK FOR SITUATION ASSESSMENT}

Defensive/Offensive Evaluation (DOE) centers on a business' core strategic objectives: (1) the defensive objective of protecting claimed product-market turf and the profit potential it affords and (2) the offensive objective of securing additional profitable turf. Of course, the best defense sometimes is an aggressive offense. And as long as 
scale economies, experience, or network externalities afford market-share leaders significant competitive advantages, growth may be a defensive imperative rather than an offensive option.

Like SWOT analysis, DOE requires delving into a business' internal and external contexts. However, DOE is much more focused and theory-driven than SWOT analysis. DOE draws from marketing thought, Porter's (1980) Five Forces Framework, Brandenburger and Nalebuff's (1996) Value Net, the resource-based view of the firm (Collis and Montgomery 1995; Peteraf 1993; Wernerfelt 1984), and transaction cost economics (Grant 2002; Williamson 1975). It is grounded in the premise that a business venture's ultimate purpose is creating shareholder value, which requires generating profits by creating customer value and controlling costs.

\subsection{DOE in Brief}

Defensive evaluation - entails probing an extant venture's vulnerability and looking for ways of strengthening the business. But intelligent vulnerability probing cannot begin until the process is understood whereby the focal business creates value for customers and, in turn, shareholders. First depicting the value creation process and profiling key resources and capabilities (R\&Cs) facilitates vulnerability probing, which has three phases:

- $\quad$ probing the internal context with the aim of understanding resource deployments and their effectiveness;

- $\quad$ probing the external noncompetitive context defined as the mass of external factors and forces capable of affecting even a monopolist's revenues or costs; and

- $\quad$ probing the competitive context by evaluating rivalry, the threat of new entrants, and the threat of substitutes.

Offensive evaluation - applies to startups and extensions of existing businesses. It centers on potential pioneering or poaching ventures. Pioneering means cultivating virgin turf, while poaching means wresting market share from rivals.

Offensive evaluation of an apparent pioneering opportunity entails subjecting a contemplated pioneering venture to vulnerability probing as if it had been launched. If pioneered turf cannot be defended or affords insufficient profit potential, then the venture's attractiveness is in doubt. Offensive evaluation of an apparent poaching opportunity entails subjecting rivals whose turf is coveted to vulnerability probing with the intent of discovering their disadvantages and exploitable weaknesses.

\subsection{Preliminaries: Depicting the Value-Creation Process and Profiling R\&Cs}

As noted in the preceding DOE overview, vulnerability probing is an aspect of both defensive and offensive evaluation. Within the context of defensive and pioneering-opportunity evaluation, the focal business is "our" existing or contemplated venture; and within the context of poaching, the focal ventures are competing enterprises. Effective vulnerability probing hinges on understanding a business' value creation process and underlying resources and capabilities (R\&Cs). Hence, it is facilitated by first depicting the value creation process graphically and/or verbally and profiling key R\&Cs.

Depicting the value-creation process - Figure 2 is a sketch of the generic customer value (CV) creation process. Products, which are a business' salable outputs of goods and/or services, are represented by benefit value $(\mathrm{BV})$, which is the monetary worth customers place on a product as a bundle of functional and psychic benefits. At the level of the individual customer, a product's BV is equivalent to the highest price the customer would pay when neither substitutes nor alternate sources of supply are available. At the market level, BV denotes aggregate BV. Further, $\mathrm{CV}=\mathrm{BV}$-price, which is tantamount to so-called consumer surplus (Baye 2003; Zeithaml 1988). The BV-cost differential is critical because firms whose products afford superior BV-cost margins are well-positioned to earn profit premiums: They can attract customers by offering superior value (BV-price) and can appropriate as profit part of the value created (price-cost). 


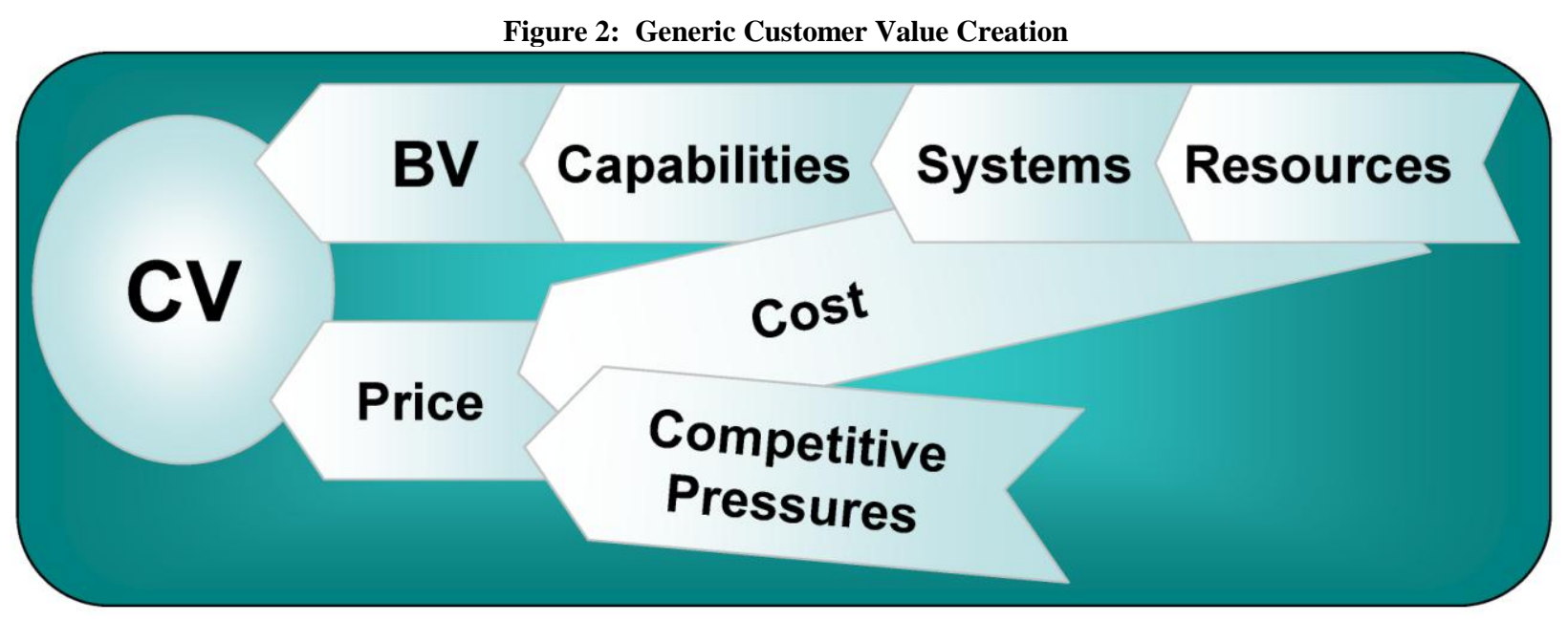

For illustrative purposes, Figure 3 maps R. C. Willey Home Furnishings' CV creation process circa 2000 (Valentin and Storey 2002). Valued benefits are shown above the dashed line. Circa 2000, they convinced myriad Utah consumers that R.C. Willey was the first and, perhaps, the only store they needed to visit when shopping for furniture, major appliances, home entertainment gear, and many other durable household items.

Systems and capabilities that generated "more bang for the customer's buck" and afforded various competitive advantages are pictured below the dashed line. They enabled R.C. Willey to reap more than twice as much revenue per square foot as rivals and, thus, realize vastly superior returns on assets and equity.

R.C. Willey's ability to create superior CV hinged substantially on size advantages within the Northern Utah market. For instance, as Utah's market-share leader in home furnishings (over 50 percent) and electronics (over 30 percent), R.C. Willey realized scale economies in logistics and advertising far beyond the reaches of competitors. As the two-way arrows and various loops in Figure 3 are intended to suggest, many advantages were mutually reinforcing. For instance, R.C. Willey spent much greater sums on advertising than competitors, yet spent much less than any serious challenger as a percentage of sales. This advantage was instrumental in generating the volume needed to secure an operating efficiency advantage, which made more money available for additional volume-generating advertising, discounts, and incentives.

Constructing a resources and capabilities profile - An illustrative resources and capabilities (R\&C) profile is shown in Table A-3 of the Appendix. It enumerates critical R\&Cs and notes their strategic significance.

\subsection{Probing the Internal Context}

Once a venture's value creation process is understood and critical R\&Cs have been profiled, analysts can proceed to evaluate the effectiveness of resource deployments. Internal probing should focus on the effects of suboptimization, horizontal scope, and vertical scope on BV, cost, and competitive position.

Suboptimization - affects BV and/or cost. For example, unwise tradeoffs diminished the BV Schlitz created. Once America's favorite beer, Schlitz damaged itself irreparably in the '70s by misguided cost cutting that compromised quality and made Schlitz easy prey (Aaker 1991; Neher 1982). Waste and some poor choices raise cost unnecessarily. For example, Coors built a brewery capable of producing 15 million barrels per year. Had three dispersed 5-million-barrel facilities been built instead, production cost would not have risen appreciably, but distribution cost would have declined greatly (Ghemawat 1999). 
Horizontal scope - affects economies of scope, which stem from spreading sunk costs across multiple products or using owned assets (e.g., a trusted brand, relevant expertise) to reduce the incremental cost of expansion, including geographic growth and making or marketing new products.

Vertical scope - i.e., degree of vertical integration - too, affects cost and competitiveness. The typical business comprises only a portion of what Porter (1985) calls a value stream. Upstream, are its suppliers; downstream are its channel partners, if any, and customers. Transaction cost economics provides a conceptual basis for assessing whether performing more or fewer value-stream functions is advantageous (Grant 2002; Williamson 1975). Vertical integration expands vertical scope, while outsourcing often narrows it.

Figure 3: R.C. Willey's Value Creation Process Circa 2000

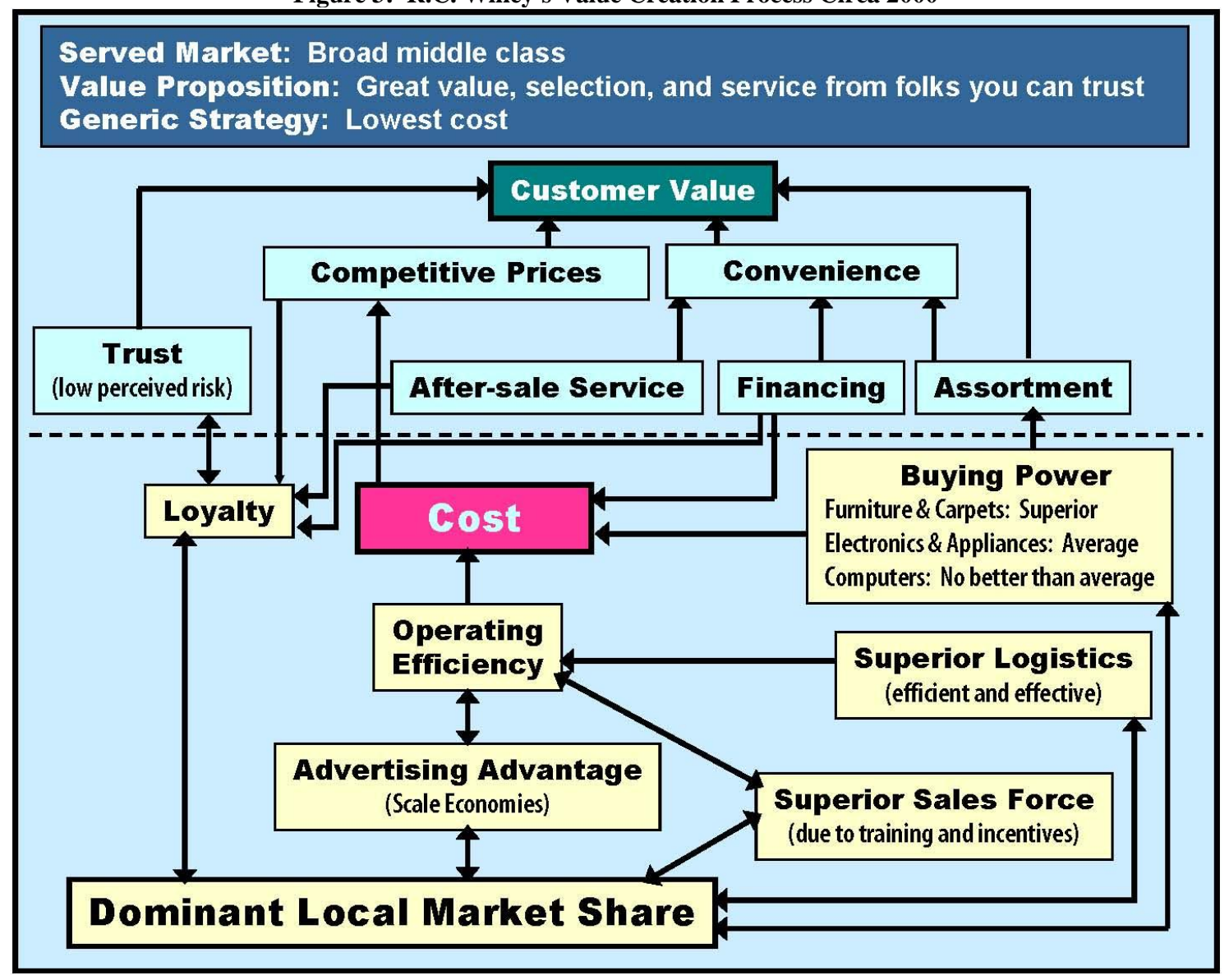

\subsection{Probing the External Context}

The external context is vast, but can be partitioned roughly into noncompetitive and competitive dimensions for expository purposes. The noncompetitive dimension consists of external particulars capable of affecting even enterprises that have no competitors, while the competitive dimension centers on threats posed by rivals, potential new entrants, and substitutes. In competitive markets, noncompetitive developments usually have competitive ramifications because they seldom affect all contestants identically or proportionately. 
Whether an external development should be viewed as noncompetitive or competitive sometimes is open to judgment and interpretation. Fortunately, how it is classified does not matter as long as its strategic implications are assessed. The noncompetitive and competitive dimensions are mere artifacts invoked to systematize scrutiny of the external context.

\subsection{Probing the Noncompetitive Dimension}

The following potential noncompetitive developments are illustrative, not exhaustive. They may affect BV and/or cost and, thus, the critical BV-cost differential.

$B V$ and the noncompetitive dimension - Various personal, societal, and technological developments may enhance or diminish a product's BV at the customer, segment, and market levels and, in turn, affect the prices, revenues, and profits the product can fetch. Consider the following examples:

- $\quad$ Autonomous preference change - Wine coolers, for instance, may have become popular not only because they were advertised heavily, but also because, for a time, drinking them was "cool." Cooler demand may have fizzled after a while simply because the product fell prey to boredom and eagerness to try something newer.

- $\quad$ Socially induced preference change - Customer preferences and needs may change in response to societal forces, including legislation. Accordingly, wine cooler sales may have declined in response to higher alcohol taxes, stricter DUI laws, pleas from Mothers Against Drunk Driving (MADD), or health warnings.

- $\quad$ Demographic changes - often affect aggregate demand, cost, and rivalry.

- Complementary interactions - Factors that impact one product often affect complementary products. For instance, sales of Apple's Macintosh computer languished until ample BV-enhancing complementary software became available (Cringely 1993). The value of space in shopping malls often depends on the complement of tenants.

- $\quad$ Learning - abates the need for some products. Demand for word processing books, for instance, has declined not only because interfaces and on-screen help have been improved, but also because using new releases differs minimally from using familiar predecessors.

- Network externalities - prevail when the BV of a product (e.g., a PC operating system) is affected substantially by the number of adopters (Arthur 1996; Grant 2002). They often reduce threats posed by new entrants and substitutes.

- $\quad$ Process innovations - often affect both BV and cost. Advances in robotics, information systems, and modular design have enabled some firms (e.g., PC makers) to exploit mass customization, which yields superior BV at costs approaching those of less satisfying standardized substitutes (Pine 1993). example:

Cost and the noncompetitive dimension - Numerous noncompetitive developments can affect cost. For

- $\quad$ Market size - commonly affects cost via scale and experience economies (Day and Montgomery 1983). In addition to reducing cost, experience may enhance product quality and, thus, BV.

- $\quad$ Cost and innovation - Innovative complements and processes often change cost structures. For instance, the Windows operating system multiplied applications development costs and risk. Hence, many small software developers went out of business as the DOS era ended (Cringely 1993).

- $\quad$ Bargaining power of suppliers - Demand for inputs, input scarcity, and availability of satisfactory substitutes greatly affect the bargaining power of suppliers (Porter 1980). For instance, in the '90s, most value created by PCs did not accrue to makers of the end product, such as IBM and Compaq. Instead, it was appropriated by two suppliers, Intel and Microsoft. Intel made scarce leading-edge CPUs, while Microsoft supplied unique operating systems - first DOS, then Windows. Over time, suppliers may gain or lose bargaining power in relation to their customers. For instance, consolidations among buyers or their suppliers can alter bargaining positions.

- $\quad$ Enabling innovations - Railroads and the Internet, for example, extended market reach and, thus, enabled many firms to realize further scale economies. Sometimes, several technological advances coalesce to render 
a new business model viable. In-home electricity, electric refrigeration, and automobiles, for instance, enabled the rise of supermarkets and precipitated the demise of corner grocery stores.

\subsection{Probing the Competitive Dimension}

Defensive competitive evaluation entails looking at other firms as potential aggressors, contemplating how they might attack, and pondering ways of repelling attacks. It requires assessing the threat of new entrants and the threat of substitutes along with disadvantages (i.e., rivals' advantages), which render a business vulnerable, and the sustainability of advantages, which afford limited protection from poachers.

Profiling competitors - Profiling each formidable actual and potential rival is a logical first step in evaluating competitive threats. To the extent accessible information permits, each competitor profile should include a graphic and/or verbal depiction of the rival's value creation process, a profile of key R\&Cs, and an assessment of advantages and disadvantages in light of R\&Cs.

Revisiting the noncompetitive dimension - Competitive vulnerability probing resumes with reexamining plausible noncompetitive developments, such as changes in market size and technology, with the aim of understanding their likely competitive impact. As noted earlier, noncompetitive developments are consequential even when rivals are absent. However, most noncompetitive developments have competitive ramifications.

- $\quad$ Changes in market size - Shrinking demand for a product category tends to intensify rivalry, at least until some contestants exit. Often superior substitutes account for shrinking product-category demand. Hence, demand for typewriters declined sharply as functionally superior affordable PC systems became available. Sometimes demand declines because needs change. For example, learning has allayed the need for word processing instruction books; simpler tax laws would weaken demand for professional tax advice and intensify rivalry among tax consultants. Market growth may weaken cost advantages. Since average cost usually declines at a decreasing rate as volume increases, cost differences between large and small contestants may narrow as markets grow.

- $\quad$ Technological advances - In the beer industry, canning and bottling systems introduced in the '40s raised fixed costs, but reduced average cost in large operations. Moreover, television gave brewers their most effective advertising medium. Both advances increased the industry's minimum efficient scale (MES). Increases in fixed cost or MES promote industry concentration and consolidation because they magnify advantages of large contestants and disadvantages of smaller rivals. Electric-arc furnaces reduced MES in the steel industry and enabled some adopters to surpass former leaders wed to more capital intensive older technologies.

Vulnerability to imitation - Imitators are poachers who endeavor to copy (with or without modification) a leading incumbent's product, business model, or strategy. Imitations need not materialize to depress profits because, when imitation is easy, incumbents face two profit-suppressing options: Discourage prospective imitators by pricing offerings so low that profit margins and entry are unattractive, or suffer the consequences of intensified rivalry.

Rather than copy pacesetters' products, imitators may try to emulate entire business models or strategies. For instance, imitating the Dell Direct Model - an exceedingly efficient integrated system of direct order placement, inventory and supplier management, and direct distribution - has been the aim of nearly every PC maker (Magretta 1998).

Imitators are apt to realize their financial objectives only if they (1) identify what needs to be copied, (2) have ready economical access to critical R\&Cs, and (3) exploit imitation without destroying profit potential.

- $\quad$ Identification - Ambiguous product recipes and strategic success formulas afford protection from aspiring imitators to the extent that they make identifying what must be imitated difficult and error prone. Ambiguity often stems from complexity (Barney 1991; Lippman and Rumelt 1982). 
- $\quad$ Accessibility - Aspiring imitators who have figured out what to copy must access needed R\&Cs at costs conducive to realizing their financial objectives. When imitative efforts progress slowly, opportunity losses mount. However, accelerating imitation usually increases out-of-pocket costs (Dierickx and Cool 1989).

- Exploitability - Imitation sometimes is easy, but unattractive because markets afford insufficient profit potential, aspiring imitators cannot generate the volume needed to benefit from large capital expenditures, or markets are too small to sustain additional contestants. Low initial profit potential repeatedly induced major manufacturers of disc drives to postpone making more compact new-generation models until upstarts had surpassed them (Christensen 1997); for lack of sales volume, R.C. Willey's competitors could not realize savings from duplicating the pacesetter's enormous distribution center (Valentin and Storey 2002); and Kmart bypassed many small towns already claimed by Wal-Mart because local demand was insufficient to sustain two similar superstores.

Vulnerability to product innovation - Technological innovations regularly spawn substitutes that afford more $\mathrm{CV}$ than older variants. Thus, digital watches have nearly displaced mechanical models; laser surgery is preferred increasingly to corrective lenses; and PC systems serve to accomplish many tasks once performed using adding machines and typewriters. Innovative substitutes often pose greater threats than imitative substitutes not only because they commonly afford superior BV at lower cost, but also because they tend to escape notice until they are formidable contenders. Network effects and switching costs sometimes afford incumbents considerable protection from innovations (Arthur 1996; Grant 2002).

Vulnerability to strategy innovation - Innovative success formulas - i.e., imaginative business models and strategies - are exemplified by the Dell Direct Model. At the time of its inception, Hiller (1983) argued that only familiar affordable standardized or readily modifiable products requiring little service could ever be marketed successfully via direct channels. Michael Dell alone grasped quickly that the PC could become such a product. Thus, while market leaders IBM and Compaq relied on conventional channels, Dell built a highly efficient integrated system of direct order placement, inventory and supplier management, and direct distribution that Dell's rivals still envy and try to imitate.

Vulnerability and time - Advantages may fade spontaneously. For instance, as demand grows, markets can sustain additional contestants. Thus, mass merchandisers operating in growing heterogeneous markets often are vulnerable to focused target marketers. Resource advantages may be lost when depleted assets cannot be replaced (e.g., expired patents) or can be replaced only with inferior substitutes or at inflated prices.

\subsection{Offensive Evaluation}

Offensive evaluation centers on potential pioneering and poaching opportunities. Neither SWOT analysis nor DOE are highly efficient search algorithms that quickly zero in on promising opportunities. Indeed, DOE's offensive evaluation phase is limited to screening potential ventures conceived apart from DOE per se. Nevertheless, value creation process diagrams and R\&C profiles can spark insight into opportunities for leveraging R\&Cs. Further, they provide backdrops for pondering generic opportunities suggested by Ansoff's (1965) well-know growth vector (a.k.a., product-market matrix).

Pioneering opportunities - The advisability of undertaking a pioneering venture depends largely on the vulnerability of pioneered turf. Thus, probing apparent pioneering opportunities entails assessing the prospects of securing, defending, and extending footholds. It entails applying defensive evaluation to a proposed venture as if it had been launched. Results may reveal ways of erecting protective barriers. However, if analyses suggest pioneered turf cannot be defended or affords too little profit potential, then the venture seems unattractive.

Poaching opportunities - Probing apparent poaching opportunities entails subjecting competitors whose turf is coveted to vulnerability probing with the aim of discovering their disadvantages and exploitable weaknesses. Much pertinent information about rivals can be found in annual reports, 10Ks, and trade articles (Porter 1983). 


\subsection{CONCLUDING COMMENTS}

Situation assessment is apt to be more illuminating when emphasis is shifted from categorizing to gaining systemic understanding. Yet, taxonomic SWOT analysis will prevail as long as it is mistakenly deemed the essence of situation assessment.

The Appendix illustrates the DOE approach to situation assessment. Analysts who prefer the SWOT structure for reporting purposes will discover that most DOE results can be placed under familiar SWOT rubrics. However, even when such reporting is possible without oversimplifying or obscuring causal relationships, the DOE investigative process is apt to yield better results than SWOT analysis because DOE ensures that meticulous scrutiny precedes classification and that classification is not mistaken for the ultimate objective, namely gaining strategic insight and systemic understanding.

\section{APPENDIX: AN ILLUSTRATIVE DOE}

\section{A1.0 Scenario}

In 1987, Alan Hall was CEO of NetLine, a small struggling software company. He attributed NetLine's troubles not to product performance, but to promotion and distribution woes. Manufacturers' reps and resellers seldom gave NetLine's goods the attention they needed to succeed; moreover, advertising, telemarketing, trade show exhibits, and demonstration software sent to resellers proved ineffective. NetLine needed its own missionary sales force, Mr. Hall surmised. Accordingly, he trained 25 temporary employees to market NetLine's products to resellers, such as CompUSA. He chose people who possessed both excellent computer and sales skills and lived within the areas they would cover.

In three months, NetLine reps visited more than 3,000 stores throughout the U.S.A., spending about 90 minutes at each outlet demonstrating products to sales personnel, answering questions, and offering marketing advice. Alan Hall was so encouraged by the way resellers responded to NetLine's troops that, in the fall of 1987, he founded TempReps (TR), an independent company dedicated to marketing clients' computer products. Early clients included both startups and notables, such as Microsoft, WordPerfect, and Hewlett-Packard.

TR operated as follows: The company organized four national campaigns per year and offered four product slots per campaign. Thus, TR could represent as many as four or as few as one client per campaign, depending on whether clients bought multiple slots. Clients generally insisted that TR not represent competing products during a campaign.

Each campaign began with tutorials conducted near TR's headquarters in Utah - clients were the teachers, TR's reps were the students. After mastering clients' products, reps returned to their territories and visited resellers for the next two months. Since reps lived in their territories, travel and lodging expenses were minimized. Even large clients often found outsourcing to TR cheaper than hiring and training additional permanent or temporary sales personnel. Generally, both clients and resellers were very pleased with TR's work.

\section{A2.0 TempReps Defensive/Offensive Evaluation Circa 1993}

Because TR's value creation process is simple and highly transparent, it was not diagramed. Instead, a benefits profile (Table A1), a summary of noncompetitive threats (Table A2), and an $R \& C$ profile (Table A3) were constructed. R\&C categories were suggested by Aaker (2005) and Hunt and Morgan (1995); annotations explain the implications of noted R\&Cs. Excerpts from a DOE report derived from these tables are shown in Table A4. Tables A1, A2, and A3 served as worksheets and are not shown in the illustrative DOE report. However, they, as well as a diagram of the value creation process, could have been included in the body of the report or as appendices. 


\section{TABLE A1: TEMPREPS BENEFITS PROFILE CIRCA 1993}

- $\quad$ TR promotes clients' products effectively to computer stores by demonstrating them to sales personnel, answering questions, and offering marketing advice. Alternate means of promoting computer products tend to be much less effective.

- $\quad$ TR's excellent reputation instills trust and reduces clients' perceived risk.

- Hiring TR in lieu of hiring and training temporary personnel affords clients flexibility, convenience, and economy.

- $\quad$ To satisfy clients, TR must refrain from demonstrating competing products during a campaign.

\section{TABLE A2: PLAUSIBLE NONCOMPETITIVE THREATS CIRCA 1993}

\footnotetext{
- Increasingly, new software will consist mostly of upgrades of familiar programs, which will curb the need for product demonstrations.

- Dominant software designs and de facto standards are apt to emerge in spreadsheets, word processing, and other applications; hence, the pool of prospective clients is apt to shrink.

- $\quad$ Mail-order retailing is apt to reduce the number of stores that sell mostly computer ware and, thus, is apt to diminish opportunities for in-store demonstrations.
}

\section{TABLE A3: TEMPREPS’ RESOURCES \& CAPABILITIES (R\&CS) PROFILE CIRCA 1993}

\section{- Financial:}

- TR has adequate financial resources. The business is not capital intensive; hence, financial resources do not afford advantages or pose formidable entry barriers.

- Physical:

- TR's effective and efficient customer-value delivery system (well-trained reps living in the territories they cover) is vital, but an unlikely source of advantage because it can be imitated easily.

- Scale is an unlikely sources of advantage because all true contenders must cover the USA.

- Critical limitation: TR cannot serve all prospective customers because competing products cannot be demonstrated during a campaign. Adding slots would not alleviate this problem, which opens a window of opportunity for new entrants.

- $\quad$ Legal and Intellectual:

$\circ \quad$ TR's business model is ingenious, but transparent, and cannot be protected by copyrights or patents. Therefore, it is readily imitable and an unlikely source of sustainable advantage or profit premiums.

- Other intellectual capital includes transparent sales and demonstration techniques. Employment contracts notwithstanding, little can be done to prevent former TR employees from becoming TR competitors by starting their own businesses modeled after TR.

- Reputation:

- TR's clients cannot risk ineffective marketing and, therefore, prefer hiring a firm with a solid track record, even if that firm charges premium prices. They are likely to consider employing a TR competitor only if (a) that competitor has developed a reputation for excellence or (b) TR has no slots available when they are needed.

- Critical weakness: TR's reputation advantage is destined to erode. Because competing products cannot be demonstrated during a campaign, TR will have to turn some eager potential customers away. Such customers provide upstarts with opportunities to build good reputations and, thus, negate TR's main advantage. 
$\circ \quad$ Doing many little things a little better than competitors (e.g., via superior execution and applying knowledge gained from serving clients) may be the key to retaining prime clients and slowing profit erosion.

- Relational:

$\circ \quad$ TR has developed excellent relationships with clients and retailers and, thus, has superior access to both clients and stores. Because developing good relationships takes time and computer stores can accommodate only a few demonstrations, TR has an advantage (probably temporary) over prospective poachers. As the innovator and first-mover, TR seized opportunities to bond with makers and resellers of computer products by delivering what it promised.

- Clients would drop TR if TR were to represent competing products during a campaign.

- Clients' switching costs are low.

- Human:

- Within the context of TR's current business, CEO Alan Hall's future value derives from his managerial and leadership skills, which will be needed to run TR. Such skills are important, but seem only moderately scarce. Unlike Alan Hall, imitators need not invent a new business model; they can easily copy TR's. To challenge TR, they do not need a CEO as innovative or visionary as Mr. Hall. A persistent poacher with entrepreneurial drive, people skills, and a keen eye on costs and the balance sheet suffices. However, taking the business beyond its current bounds or transforming it to stay a step ahead of imitators will require Mr. Hall's rare innovative mind and entrepreneurial zeal.

- Qualified representatives are vital, but only moderately scarce and, therefore, are unlikely sources of competitive advantage.

- Employees are mobile and, thus, could start or join competing firms; clauses that would prevent them from doing so seem ineffective. Prospective clients may perceive hiring a TR competitor staffed by former TR employees as only slightly more risky than hiring TR.

- Organizational and systemic resources:

- TR's routines and working relationships are critical, but they also seem straightforward and transparent. Not every challenger will be able to develop them, but some are apt to succeed within a few months of entering the business.

- Informational resources:

$\circ \quad$ Much pertinent information is available to anyone. But challengers may not be adept at converting accessible information into actionable knowledge. In view of Mr. Hall's talents, TR may excel in using customer information to tailor services dynamically to clients' needs and thereby create loyalty.

The DOE report (Table A4) notes several ominous noncompetitive prospects and portrays reputation as TR's main strength and principal source of competitive advantage. Further, it notes that the TR concept is highly imitable and that the reputation gap between TR and challengers is likely to narrow along with profit margins. The offensive section of the report conveys that only iffy opportunities came to mind. 


\title{
TABLE A4: EXCERPTS FROM AN ILLUSTRATIVE DEFENSIVE/OFFENSIVE EVALUATION
}

\author{
Tempreps Defensive/Offensive Evaluation (Circa 1993)
}

TempReps (TR) demonstrates PC software and hardware in computer retail stores (e.g., CompUSA) for clients that include numerous startups and a few notables, such as Microsoft, Lotus, and WordPerfect . . TR pioneered this industry ... Clients are eager to hire TR because TR's in-store demonstrations are more effective than other promotional options ... Evaluations of TR's defensive and offensive positions follow.

\section{Defensive Evaluation}

Noncompetitive issues - Demand for software demonstrations is likely to diminish soon for three reasons: (1) Dominant designs, or de facto standards, are likely to emerge in most software categories, which will spark a shakeout that very likely will reduce the number of prospective clients. (2) Truly new software is seen less often than in the past; upgrades, which comprise most new software, seldom require demonstration. (3) Direct selling is likely to reduce the number of conventional computer stores and, thus, diminish opportunities for providing in-store demonstrations....

Competitive issues - Currently, direct competitors do not exist. . . Clients have found TR's services very effective and, therefore, value them greatly. However, TR's services are highly imitable. The company's reputation is its main source of competitive advantage; it creates value for clients by reducing perceived risk. ... So far, reputation has enabled TR to keep competitors at bay. Unfortunately, TR cannot serve all clients who want its services. If TR were to represent all prospective clients, it would have to represent competing products at the same time, which few clients would tolerate. This predicament leaves a window of opportunity open for poachers. Moreover, it portends that the reputation gap between competitors and TR is destined to narrow dramatically because a few competitors are bound to gain access to clients and demonstrate their effectiveness. . . Alan Hall's corps of demonstrators operates very effectively and efficiently, but can be replicated easily by poachers. . . . Former TR employees who understand the business and have access to TR's clients are likely to become poachers. . . TR's competitive advantages seem destined to erode despite CEO Hall's genius and unbounded energy. . . . Measures that may slow erosion include using information gained from serving clients advantageously to continually improve solutions to clients' problems ...

\section{Offensive Evaluation}

TR may be able to leverage its reputation and knowledge by targeting additional customer segments, such as corporate and institutional IT directors or new geographic areas (e.g., Europe, Asia, South America) . . . Reconnaissance visits to several countries around the world would shed light on the extent to which culture, infrastructure, and other factors limit opportunities beyond the U.S.A. . . S Sales of products other that PC ware may respond to in-store demonstrations. For instance, electronic games . . However, finding additional products that would sell much more briskly if demonstrated in stores or that have the sales and profit potential of PC ware seems unlikely for several reasons: ....

\section{Strategic Implications}

... cement relationships with clients ... search for opportunities to apply the TR concept to other products . . . realize that in-person in-store PC software and hardware demonstrations will not be needed indefinitely; hence, at some point, abandoning this particular business and reinvesting elsewhere may be a better option than trying to maintain it... 


\section{A3.0 Epilogue}

By and large, TR's fortunes materialized along the lines foreseen: Reputable competitors emerged from the ranks of former TR employees and gained footholds because TR could serve only a limited number of clients in a timely fashion. As competition intensified and various anticipated noncompetitive developments reduced demand for in-store demonstrations, profits eroded.

In 1992, Alan Hall commented that TR was capable of generating \$10 million in sales per year, but would never produce $\$ 100$ million. He was correct. However, he successfully transformed TR into MarketStar, a prospering international provider of integrated marketing solutions serving clients who prefer outsourcing some or all of their marketing activities. MarketStar's menu of offerings includes merchandising, online customer service, planning, and market research. See www.marketstar.com for details.

\section{REFERENCES}

1. $\quad$ Aaker, David A., Managing Brand Equity, Free Press, New York, 1991.

2. $\quad$ Aaker, David A., Strategic Market Management, Wiley \& Sons, Inc., New York, 2005.

3. Ansoff, H. Igor, Corporate Strategy, McGraw-Hill, New York, 1965.

4. Arthur, W. Brian, "Increasing Returns and the New World of Business," Harvard Business Review, Vol. 74, July-August, pp. 100-109, 1996.

5. Barney, Jay B., "Firm Resources and Sustained Competitive Advantage," Journal of Management, 17, March, pp. 99-120, 1991.

6. Barney, Jay B., Gaining and Sustaining Competitive Advantage, Prentice-Hall, Upper Saddle River, NJ, 2002.

7. Baye, Michael, Managerial Economics, McGraw-Hill, Boston, MA, 2003.

8. Brandenburger, A. M., and Nalebuff, B. J., Co-opetition, Currency Doubleday, New York, 1996.

9 Buzzell, Robert D., Bradley T. Gale, and Ralph G. M. Sultan, "Market Share - a Key to Profitability," Harvard Business Review, Vol. 53, January-February, pp. 97-106, 1975.

10. Christensen, Clayton M., The Innovator's Dilemma, Harvard Business School Press, Boston, MA, 1997.

11. Collis, David J. and Cynthia A. Montgomery, "Competing on Resources: Strategy in the 1990s," Harvard Business Review, Vol. 73, July-August, pp. 118-128, 1995.

12. Cringely, Robert X., Accidental Empires, Harper-Collins, New York, 1993.

13. Day, George S., Strategic Market Planning: The Pursuit of Competitive Advantage, West Publishing, St. Paul, MN, 1984.

14. Day, George S. and David B. Montgomery, "Diagnosing the Experience Curve," Journal of Marketing, Vol, 47, Spring, pp. 44-58, 1983.

15. Dierickx, Ingemar and Karel Cool, "Asset Stock Accumulation and Sustainability of Competitive Advantage, Management Science, Vol. 35, December, pp. 1504-1511, 1989.

16. Ghemawat, Pankaj, "Sustainable Advantage," Harvard Business Review, Vol. 64, September-October, pp. 53-58, 1986.

17. Ghemawat, Pankaj, "Adolph Coors in the Brewing Industry: Teaching Note, Note 5-388-018, Harvard Business Press, Boston, MA, 1999.

18. Glazer, Rashi, "Marketing in an Information-intensive Environment: Strategic Implications of Knowledge as an Asset," Journal of Marketing, Vol. 55, October, pp. 1-19, 1991.

19. Grant, Robert M., Contemporary Strategy Analysis, Blackwell Publishers, Malden, MA, 2002.

20. Hill, Terry and Roy Westbrook, "SWOT Analysis: It's Time for a Product Recall," Long Range Planning, Vol. 30, February, pp. 46-52, 1997.

21. Hiller, Terry R., "Going Shopping in the 1990s: Retailing Enters the Future," The Futurist, December, pp. 63-68, 1983.

22. Hunt, Shelby D. and Robert M. Morgan, “The Comparative Advantage Theory of Competition," Journal of Marketing, Vol. 59, April, pp. 1-15, 1995. 
23. Jacobson, Robert and David A. Aaker, "Is Market Share All That It's Cracked Up to Be?" Journal of Marketing, Vol. 49, fall, pp. 11-22, 1985.

24. Kotler, Philip, Marketing Management, Prentice-Hall, Upper Saddle River, NJ, 2003.

25. Lippman, S. A. and Richard P. Rumelt, "Uncertain Imitability: An Analysis of Interfirm Differences in Efficiency Under Competition,” Bell Journal of Economics, Vol. 13, August, pp. 418-438, 1982.

26. Magretta, Joan, "The Power of Virtual Integration: An Interview With Dell Computer's Michael Dell," Harvard Business Review, Vol. 76, March-April, pp. 73-84, 1998.

27. Mintzberg, Henry, The Rise and Fall of Strategic Planning, Free Press, New York, 1994.

28. Neher, Jacques, "What Went Wrong?" in Strategic Market Decisions, Keith K. Cox and Vern J. McGinnis, eds., Prentice-Hall, Englewood Cliffs, NJ, pp. 313-323, 1982.

29. Peteraf, Margaret A., "The Cornerstones of Competitive Advantage: A Resource-Based View," Strategic Management Journal, Vol. 14, May-June, pp. 179-191, 1993.

30. Pine, Joseph B., II, Mass Customization: The New Frontier of Business Competition, Harvard Business School Press, Boston, MA, 1993.

31. Porter, Michael E., Competitive Strategy, Free Press, New York, 1980.

32. Porter, Michael E., "Analyzing Competitors: Predicting Competitor Behavior and Formulating Offensive and Defensive Strategy," in Policy, Strategy, and Implementation, Milton Leontiades, ed., Random House, New York, pp. 192-209, 1983.

33. Porter, Michael E., Competitive Advantage, Free Press, New York, 1985.

34. Porter, Michael E., "What Is Strategy," Harvard Business Review, Vol. 74, November-December, pp. 61-78, 1996.

35. Srivastava, Rajendra K., Tasadduq A. Shervani, and Liam Fahey, "Market-Based Assets and Shareholder Value: A Framework for Analysis," Journal of Marketing, Vol. 62, January, pp. 2-18, 1998.

36. Valentin, E. K., "SWOT Analysis from a Resource-Based View," Journal of Marketing Theory and Practice, Vol. 9, spring, pp. 54-68, 2001.

37. Valentin, E.K. and Jerald T. Storey, "R.C. Willey Home Furnishings," Business Case Journal, Vol.10, summer, pp. 99-116, 2002.

38. Wernerfelt, Birger, "A Resource-based View of the Firm," Strategic Management Journal, Vol. 5 NovemberDecember, pp. 170-80, 1984.

39. Williamson, Oliver E., Markets and Hierarchies, Free Press, New York, 1975.

40. Zeithaml, Valerie A., "Consumer Perceptions of Price, Quality, and Value: A Means-End Model and Synthesis of Evidence," Journal of Marketing, Vol. 52, July, pp. 2-22, 1988. 